\title{
Anatomy teaching by only medically qualified faculty is infeasible
}

\author{
Terkuma Chia ${ }^{1}$ (1)
}

Received: 18 February 2020 / Accepted: 4 March 2020 / Published online: 12 March 2020

○) Springer-Verlag France SAS, part of Springer Nature 2020

\section{Dear Editor,}

I have read with keen interest the article published in your revered journal titled "Model pedagogy of human anatomy in medical education"' [1]. I noted one of the strong points advocated by the authors for implementing their model was the restriction of non-medically qualified faculty from teaching anatomy. This position is advocated without consideration of evidence pointing to the lack of anatomy teachers globally.

Even with medically and non-medically qualified faculty put together data indicate that teacher to student ratios are high [2]. More so that very few medical students intend to take anatomy as career following their qualification [3]. How then do institutions sustain anatomy teaching using only medically qualified individuals?

The importance of teaching of Anatomy in clinical context cannot be overemphasized. However, the implementation of the author-suggested model would be problematic especially in countries that lack sufficient numbers of medically qualified faculty. Therefore, non-medically qualified faculty can teach anatomy alongside medically qualified faculty. Besides, efficient delivery of anatomical knowledge to medical students by whichever faculty is paramount. This can easily be achieved via pedagogic research into problem areas followed by pedagogic training for faculty. Interest in this aspect of anatomy is relatively new but since its inception, remarkable results are being recorded [4]. Hence, scaling up is strongly recommended across the globe.

\section{References}

1. Kumar R, Singh R (2019) Model pedagogy of human anatomy in medical education. Surg Radiol Anat. https://doi.org/10.1007/ s00276-019-02331-7

2. Kramer B, Pather N, Inhunwo AO (2008) Anatomy: spotlight on Africa. Anat Sci Educ 1(3):111-118

3. Onakpoya OH, Onakpoya UU, Adereti GE (2009) The prospect of anatomy as a career choice among clinical year medical students in Nigeria. Ann Afr Med 8(2):90-94

4. Smith CF, Stabile RI, Finn GM (2018) Pedagogic research in anatomical sciences: a best practice guide. Eur J Anat 22(3):257-268

Publisher's Note Springer Nature remains neutral with regard to jurisdictional claims in published maps and institutional affiliations.
Terkuma Chia

terkumachia@hotmail.com

1 Department of Anatomy, Faculty of Basic Medical Sciences, College of Health Sciences, Nile University of Nigeria, Abuja, Nigeria 